\title{
QUEEN'S
UNIVERSITY
BELFAST
}

\section{Evaluation of an alternative spectroscopic approach for aflatoxin analysis: Comparative analysis of food and feed samples with UPLC- MS/MS}

Campbell, K., Ferreira Cavalcante, A. L., Galvin-King, P., Oplatowska-Stachowiak, M., Brabet, C., Metayer, I., Montet, D., Haughey, S. A., \& Elliott, C. T. (2017). Evaluation of an alternative spectroscopic approach for aflatoxin analysis: Comparative analysis of food and feed samples with UPLC-MS/MS. SENSORS AND ACTUATORS B-CHEMICAL, 239, 1087-1097. http://10.1016/j.snb.2016.08.115

\section{Published in:}

SENSORS AND ACTUATORS B-CHEMICAL

Document Version:

Early version, also known as pre-print

Queen's University Belfast - Research Portal:

Link to publication record in Queen's University Belfast Research Portal

Publisher rights

Copyright 2016 The Authors

\section{General rights}

Copyright for the publications made accessible via the Queen's University Belfast Research Portal is retained by the author(s) and / or other copyright owners and it is a condition of accessing these publications that users recognise and abide by the legal requirements associated with these rights.

\section{Take down policy}

The Research Portal is Queen's institutional repository that provides access to Queen's research output. Every effort has been made to ensure that content in the Research Portal does not infringe any person's rights, or applicable UK laws. If you discover content in the Research Portal that you believe breaches copyright or violates any law, please contact openaccess@qub.ac.uk. 


\section{Evaluation of an alternative spectroscopic approach for aflatoxin analysis: Comparative analysis of food and feed samples with UPLC-MS/MS}

Katrina Campbell ${ }^{1 *}$, Ana L. Ferreira Cavalcante ${ }^{1}$, Pamela Galvin-King ${ }^{1}$, Michalina OplatowskaStachowiak ${ }^{1}$, Catherine Brabet ${ }^{2}$, Isabelle Metayer ${ }^{2}$, Didier Montet ${ }^{2}$, Simon A. Haughey ${ }^{1}$, Christopher T. Elliott ${ }^{1}$

${ }^{1}$ Institute for Global Food Security, School of Biological Sciences, Queen's University, David Keir Building Stranmillis Road, Belfast, UK BT95AG

${ }^{2}$ Centre de coopération Internationale en Recherche Agronomique pour le Développement, (CIRAD), UMR Qualisud, 73 rue Jean-François Breton, 34398 Montpellier Cedex 5, France

*Corresponding author:

Dr Katrina Campbell

Tel: +44 (0) 2890976535

Fax: +44 (0)2890976513

E-mail: katrina.campbell@qub.ac.uk 


\section{Abstract}

Increasing research has highlighted the effects of changing climates on the occurrence and prevalence of toxigenic Aspergillus species producing aflatoxins. There is concern of the toxicological effects to human health and animal productivity following acute and chronic exposure that may affect the future ability to provide safe and sufficient food globally. Considerable research has focused on the detection of these toxins, based on the physicochemical and biochemical properties of the aflatoxin compounds, in agricultural products for human and animal consumption. As improvements in food security continue more regulations for acceptable levels of aflatoxins have arisen globally; the most stringent in Europe. These regulations are important for developing countries as aflatoxin occurrence is high significantly effecting international trade and the economy. In developed countries analytical approaches have become highly sophisticated, capable of attaining results with high precision and accuracy, suitable for regulatory laboratories. Regrettably, many countries that are affected by aflatoxin contamination do not have resources for high tech HPLC and MS instrumentation and require more affordable, yet robust equally accurate alternatives that may be used by producers, processors and traders in emerging economies. It is especially important that those companies wishing to exploit the opportunities offered by lucrative but highly regulated markets in the developed world, have access to analytical methods that will ensure that their exports meet their customers quality and safety requirements.

This work evaluates the ToxiMet system as an alternative approach to UPLC-MS/MS for the detection and determination of aflatoxins relative to current European regulatory standards. Four commodities: rice grain, maize cracked and flour, peanut paste and dried distillers grains were analysed for natural aflatoxin contamination. For B1 and total aflatoxins determination the qualitative correlation, above or below the regulatory limit, was good for all commodities with the exception of the dried distillers grain samples for B1 for which no calibration existed. For $\mathrm{B} 1$ the quantitative $\mathrm{R}^{2}$ correlations were $0.92,0.92,0.88(<250 \mu \mathrm{g} / \mathrm{kg})$ and 0.7 for rice, maize, peanuts and dried distillers grain samples respectively whereas for total aflatoxins the quantitative correlation was $0.92,0.94,0.88$ and 0.91 . The ToxiMet system could be used as an alternative for aflatoxin analysis for current legislation but some consideration should be given to aflatoxin M1 regulatory levels for these commodities considering the high levels detected in this study especially for maize and peanuts. 
Keywords: ToxiMet, UPLC-MS/MS, Aflatoxin, food and feed, spectroscopy, Aflatoxin M1

\section{Introduction}

Aflatoxins, a group of mycotoxins first discovered after the occurrence of Turkey $\mathrm{X}$ disease in UK in the 1960s, are a most influential group of contaminants of concern for food security [1]. They are naturally occurring metabolites produced commonly by the toxigenic strains of the fungal species Aspergillus [2]. Several factors favour fungal growth including environmental, chemical and biological parameters. Two important factors affecting growth are the temperature and relative humidity with growth occurring between $10-35^{\circ} \mathrm{C}$, optimally 30 $35^{\circ} \mathrm{C}$, and relative humidity optimally above $85 \%$ [3]. Due to an awareness of the risks of climate change to food security, increasing studies are emerging examining the role of climatic factors on specific fungal species and their gene expression for toxin production $[4,5]$.

Aflatoxins are organic chemicals known as difuranocoumarins. They are classified into two broad groups according to their chemical structure; the difurocoumarocyclopentenone series (AFB1, AFB2, AFB2A, AFM1, AFM2, AFM2A and aflatoxicol) and the difurocoumarolactone series (AFG1, AFG2, AFG2A, AFGM1, AFGM2, AFGM2A and AFB3). The four major agriculturally important aflatoxins: B1, B2, G1, G2 were identified from their significant direct contamination of foods and feeds (Figure 1). These toxins have minor modifications in structure and molecular formulas and form a unique group of heat stable highly oxygenated, naturally occurring heterocyclic compounds. Aflatoxins B2 and G2 were established as the dihydroxy derivatives of B1 and G1, respectively. The aflatoxins display potency of toxicity, carcinogenicity, mutagenicity in the order of AFB1 > AFG1 > AFB2 > AFG2 [6]. Chemically the double bond of the dihydrofuran and the elements linked to the coumarin moiety are of importance in producing biological effects. The aflatoxins fluoresce strongly in ultraviolet light due to the ring structure (ca. $365 \mathrm{~nm}$ ). The B label of aflatoxins B1 and B2 resulted from the exhibition of blue fluorescence under UV-light $(425 \mathrm{~nm})$, while the G label refers to the yellowgreen fluorescence of the relevant structures under UV-light $(540 \mathrm{~nm})$. It has been reported that Aspergillus flavus, Emericella astellata, E. venezuelensis and A. pseudotamarii produce B1 and B2 while A. parasiticus, A. nomius, A. bombycus, A. miniscleotigenes, A. arachidicola produce $B 1, B 2, G 1$ and $G 2$ toxins [7]. The aflatoxins $M 1$ and $M 2$, two additional metabolic products were first isolated from milk of lactating animals fed aflatoxin preparations; hence, 
the $\mathrm{M}$ label [8]. Aflatoxin M1 is 4-hydroxy aflatoxin $\mathrm{B} 1$ and aflatoxin $\mathrm{M} 2$ is 4-dihydroxy aflatoxin B2 [9] and their toxic potency falls between B1 and $\mathrm{G} 1$ and B2 and G2 respectively.

Due to a combination of the optimal conditions required for fungal growth and susceptibility of the staple diets to Aspergillus growth these toxins tend to be most prevalent in tropical and subtropical regions, most of which are developing countries, causing severe negative impacts to food security $[10,11]$. Since their identification the health and economic impacts of the occurrence, legislation and prevention of aflatoxin in feed and food have been well documented [12-19]. The most significant step was in 1993 when the International Agency for Research on Cancer (IARC) classified 'naturally occurring mixes of aflatoxins' as a Group 1 carcinogen, meaning that sufficient evidence exists to link aflatoxin exposure to cancer in humans [20]. Aflatoxin exposure leads primarily to a condition known as aflatoxicosis, a hepatic disease. Research suggests the exposure and susceptibility of individuals to aflatoxins from food contamination varies considerably depending on geographical location, type of diet, awareness of aflatoxin contamination, socioeconomic status, age, sex, nutritional status and/or concurrent exposure to other causative agents such as viral hepatitis (HBV) or parasite infestation. In animals, variations occur between species but aflatoxins are known to cause liver damage, anaemia, jaundice, gastrointestinal dysfunction, reduced feed utilization and efficiency with decreased milk and egg production, recurrent infection as a result of immunity suppression (e.g. salmonellosis), reduced reproductively and embryo toxicity in animals consuming low dietary concentrations. All ages are affected but to different degrees for different species with the young most susceptible. Nursing animals may be affected as a result of the conversion of aflatoxin B1 to the metabolite aflatoxin M1 excreted in milk.

To limit aflatoxin exposure, over 100 nations worldwide have set maximum tolerated levels of aflatoxin in food [21]. These standards offer public health protection in industrialized nations, but arguably have little effect in less developed countries through a lack of regulatory systems for aflatoxin monitoring and control. The US Food and Drug Administration has established specific guidelines on acceptable levels of aflatoxins in human food and animal feed by establishing action levels that allow for the removal of violative lots from commerce. In the US the action level for human food and cereals are $20 \mathrm{ppb}$ total aflatoxins, with the exception of milk which has an action level of $0.5 \mathrm{ppb}$ for aflatoxin M1. In Europe the maximum levels of aflatoxins for food consumption are generally lower as laid down in the Commission Regulation (EC) No 1881/2006, as amended by Commission Regulation (EU) No 165/2010 and 
Commission Regulation (EU) No 1058/2012 [22-24]. Therefore, the maximum levels for aflatoxin B1, the sum of aflatoxins B1, B2, G1 and G2 (known as Total) and aflatoxin M1 are established therein varying with commodity and its use.

Aflatoxins have commonly been detected by their photo physical properties such as absorption and emission spectra. Recent developments in the detection and determination for aflatoxins have been reviewed highlighting the advantages and disadvantages between approaches [25]. In brief, the analysis of aflatoxins in food and feed includes chemically based analytical methods such as the AOAC thin layer chromatography method, capillary electrophoresis, high performance liquid chromatography or liquid chromatography coupled to mass spectrometry. These methods are primarily high cost requiring trained laboratory staff and facilities for accurate quantitative results. Non-invasive spectroscopy or hyperspectral imaging-based methods demonstrate potential for screening large samples contaminated with aflatoxins but cannot produce quantifiable results. Immunological methods such as enzyme linked immunosorbent assays, lateral flow devices and biosensor technology offer a low cost advantage but raise concerns in reliable repeatable detection and identification of individual toxin analogues. Due to the poor economic status and low education levels in developing countries, cost-effective quantifiable methods are required that will be easy to implement. The ToxiMet System first described in [26] has now been developed further, involving the introduction of new ToxiTrace and ToxiTrace cartridges and a substantially redesigned ToxiQuant instrument, a spectroscopic device which simultaneously identifies and quantitatively measures the individual aflatoxins by employing advanced spectroscopic and proprietary chemometric procedures. The device is constructed with the understanding that radiation of certain wavelengths excites certain mycotoxin contaminants such as aflatoxin to fluoresce. The wavelength of the emitted fluorescent light from the contaminant is significantly different (usually longer) than the excitation wavelength. On the theory that the amount of light emitted is proportional to the amount of the contaminant, a measurement of the amount of light emitted can be utilized to quantify the amount of target contaminant, such as aflatoxin, immobilized in a sample cartridge. Using the device involves the extraction of a contaminant such as aflatoxin from food, the immobilisation of the contaminant as a layer in a columnar packing, the illumination of the band, typically with UV radiation, at an applicable wavelength to excite the emission of fluorescent light by the band, the detection of the fluorescence and the conversion of the detected signal into a direct measurement of the concentration of the contaminant (typically in parts per billion) [27].Therefore, the analytical sequence for the ToxiMet System is composed of four main steps: sample extraction; sample clean-up (using the ToxiSep cartridge); analyte immobilisation (on a ToxiTrace cartridge); followed by simultaneous measurement of the individual, immobilised toxins by the ToxiQuant instrument, without the need for 
chromatographic separation. The aim of the study was the comparative analysis of maize, rice and peanut samples and distillers grains for the determination of total aflatoxins concentration and individual analogues B1, B2, G1 and G2 to determine the feasibility of the ToxiMet system relative to state of the art LC-MS/MS.

\section{Materials and methods}

\section{Materials}

Samples: Peanut paste $(n=71)$, rice grains $(n=88)$ and maize cracked and flour $(n=79)$ samples (261-560 g each) used directly for human consumption were collected in the main markets of Abidjan, Bouaké and Korhogo in the Ivory Coast and kept at $-20^{\circ} \mathrm{C}$ until sample preparation. Dried distillers grains $(n=22)$ were sourced in Northern Ireland. All samples were analysed using both the Toximet System and UPLC-MS at the Institute for Global Food Security at Queen's University, Belfast.

Sample Preparation: Sample preparation was aimed at obtaining homogeneous samples. Frozen rice grain and cracked maize samples were milled in a grinder Retsch ZM 200 using a 1-mm sieve. The milled samples as well as the maize flour samples were homogenized during 30 minutes in a Chopin MR2L mixer. Peanut paste samples were thawed and homogenized during 15 minutes in a Thermomix VORWERK TM 21 by selecting the speed 2.5. The equipment was cleaned thoroughly between samples to prevent carry over contamination from sample to sample. Aliquots of the homogenized samples $(70 \mathrm{~g})$ were kept at $-20{ }^{\circ} \mathrm{C}$ until mycotoxin analysis and the same aliquot was used for both methods of analysis in the study.

ToxiMet System: ToxiSep and ToxiTrace cartridges were obtained from ToxiMet, UK. HPLC grade methanol, phosphate buffered saline (PBS) tablets (P4417) were purchased from Sigma Aldrich. Whatman No 41 and GF/A filter paper were obtained from GE Healthcare.

UPLC-MS/MS: LC-MS grade acetonitrile (ACN) (34967-2.5L); LC-MS grade methanol (349662.5L); formic acid for mass spectrometry $98 \%$ (94318-50mL-F), ammonium hydroxide solution $\geq 25 \%$ in water (44273-100mL-F), magnesium sulphate $\geq 99.5 \%$ (M7506-500g), DMSO $\geq 99.9 \%$ (D8418-50mL) and amber vials (27000), Aflatoxins B2, G1, G2 and M1 were obtained from Sigma-Aldrich (Dorset, UK). Aflatoxin B1 was from Romer Labs (Tulln, Austria). A Bondesil C18 $40 \mu \mathrm{m}$ (29041013) was purchased from Agilent (Berkshire, UK). PTFE syringe filters 
(WHA67840402 Whatman Puradisc 4 syringe filter $0.2 \mu \mathrm{m}$ PTFE) and polypropylene tubes $(50 \mathrm{~mL}$ and $15 \mathrm{~mL})$ (TPPA91051) were obtained from VWR. Sodium chloride (S/3120/53) was obtained from Fischer chemicals. The water used was supplied from an in-house $18 \mathrm{M}^{\prime} \Omega$ Millipore water system, Millipore Ltd, (Hertfordshire, UK).

\section{Methods}

\section{ToxiMet System Analysis}

Sample extraction: Each sample $(25 \mathrm{~g})$ was mixed with sodium chloride $(2.5 \mathrm{~g})$ followed by the addition of deionised water $(40 \mathrm{~mL})$ and blended for 2 minutes in a Sterilmixer 12 blender. The blender was cleaned thoroughly between each sample. Methanol HPLC Grade $(60 \mathrm{~mL})$ was then added and blended into the mixture. The solution was filtered through Whatman No 41 filter paper and an aliquot of extract $(20 \mathrm{~mL})$ was diluted with PBS solution $(40 \mathrm{~mL})$ and mixed. This solution was then filtered through Whatman GF/A filter paper.

ToxiSep Clean Up Procedure: The ToxiSep cartridges were allowed to settle in an upright position for one hour at room temperature and positioned on a vacuum manifold. The red cap of the ToxiSep Aflatoxin cartridge was removed, the column tapped until the air bubbles dislodged and travelled to just underneath the frit. An air tight seal was formed. The lower cap was removed with the adaptor and reservoir fitted to the ToxiSep clean-up cartridge. An aliquot of the extract solution $(24 \mathrm{~mL})$ was added slowly to the reservoir and allowed to pass through the ToxiSep cartridge at a flow of $3 \mathrm{~mL} / \mathrm{min}$. The cartridge was then washed with PBS $(20 \mathrm{~mL})$ at a flow of $5 \mathrm{~mL} / \mathrm{min}$. Excess PBS was removed under high vacuum from the ToxiSep cartridge for 2-5 seconds. The retained aflatoxins were eluted into an amber volumetric flask $(10 \mathrm{~mL})$ using methanol HPLC grade $(1 \mathrm{~mL})$ followed by $1 \mathrm{ml}$ of water at a flow rate of 1 drop per second. The extract was diluted to $10 \mathrm{ml}$ on addition of water to the volumetric flask. The diluted elute was filtered through a $25 \mathrm{~mm}$ syringe filter. The first $2 \mathrm{~mL}$ was discarded into the waste beaker and the remainder collected into a $10 \mathrm{ml}$ amber flask.

ToxiTrace Immobilisation: The ToxiTrace cartridge was conditioned with methanol HPLC grade $(0.2 \mathrm{~mL})$ followed by $10 \%$ methanol $(0.2 \mathrm{~mL})$. An aliquot of the filtered sample extract $(2.0 \mathrm{~mL})$ was loaded onto the column which was then washed using $10 \%$ methanol $(0.4 \mathrm{~mL})$. The washing was complete when $50 \%$ of the solvent had passed through the cartridge. 
Quantification: The Toxitrace cartridge was plugged and inserted into the ToxiQuant instrument (ToxiMet, UK) within one hour of preparation and analysed for aflatoxins by selecting the specific commodity from the on-screen menu. For dried distillers grains there was no specific option for the analysis of this sample type therefore there these samples were analysed using the option of maize. The aflatoxin results B1, B2, G1, G2 and total aflatoxins are recorded for each sample immediately.

\section{UPLC-MS/MS Analysis}

Sample preparation: The sample preparation was based on the QUEChERS method $[28,29]$ with some modifications [30]. Briefly, $1 \mathrm{~g}$ of homogenised sample was soaked with $5 \mathrm{~mL}$ of $2 \%$ formic acid in water for 30 min followed by vortex mixing with $5 \mathrm{~mL}$ of acetonitrile using a DVX-2500 multi-tube vortexer set at a speed of 1000 for $30 \mathrm{~min}$. The separation of the water from organic phase was achieved by addition of $2 \mathrm{~g}$ of magnesium sulphate and $0.5 \mathrm{~g}$ of sodium chloride and hand shaking for $30 \mathrm{sec}$ followed by 5 min centrifugation at $4000 \mathrm{~g}$. The upper organic layer $(2 \mathrm{~mL})$ was further purified by shaking for $30 \mathrm{sec}$ with $0.1 \mathrm{~g}$ C18 silica sorbent and $0.3 \mathrm{~g}$ of magnesium sulphate. After centrifuging at $4000 \mathrm{~g}$ for $1 \mathrm{~min}$, an aliquot of extract $(1 \mathrm{~mL})$ was transferred to a MS vial and DMSO $(200 \mu \mathrm{L})$ added. The solvent was evaporated off under nitrogen for approximately 45-60 min at room temperature. LC-MS/MS grade methanol $(800 \mu \mathrm{L})$ was added and the sample filtered using a $0.22 \mu \mathrm{m}$ filter.

Calibration: Matrix matched calibration curves were prepared with each batch of samples and used for calibration. Blank maize flour, rice flour and peanut paste samples previously tested and confirmed free from aflatoxins were used. An 8 point standard calibration curve in the range 0 to $50 \mu \mathrm{g} / \mathrm{kg}$ is prepared by spiking known blank materials with aflatoxin working solutions before extraction.

UPLC-MS/MS: A Waters Acquity UPLC system coupled to Waters Xevo TQ-S triple quadruple mass spectrometer was used (Waters, Milford, USA). The data were analyzed using TargetLynx software. The column used was CORTECS UPLC C18 $1.6 \mu \mathrm{m}, 2.1 \times 100 \mathrm{~mm}$ (Waters, Milford, USA). The mobile phase A was $1 \mathrm{mM}$ ammonium formate $\mathrm{pH} 6.5$ in Milli-Q water and mobile phase $B$ was $1 \mathrm{mM}$ ammonium formate in methanol:acetonitrile (50:50). The gradient elution at a flow rate $0.4 \mathrm{~mL} / \mathrm{min}$ started at $1 \%$ mobile phase $B$ and increased linearly to $99 \%$ in 10 
minutes, followed by $4 \mathrm{~min}$ equilibration. The injection volume was $1 \mu \mathrm{L}$. The mass spectrometer was operated in the positive electrospray ionization mode and the parameters were as follows: capillary voltage $1.5 \mathrm{kV}$, source temperature $150^{\circ} \mathrm{C}$, desolvation temperature $500^{\circ} \mathrm{C}$, desolvation gas flow $1000 \mathrm{~L} / \mathrm{h}$. The MS/MS conditions for aflatoxins are presented in Table 1 and Figure 2 shows the retention time separation and multiple reaction monitoring (MRM) transitions of the 5 aflatoxins (B1, B2, G1, G2 and M1) using UPLC-MS/MS. The toxins were quantified by interpolation from a matrix-matched calibration curve (spiked before extraction so results were corrected for recoveries). For samples whereby the toxin concentration was above the upper calibration range these were diluted in blank matrix and re-analysed.

\section{Results and discussion}

As aflatoxins are reported to be genotoxic carcinogens, it is important to limit their total content in food and animal feed by complying with legislation for given commodities. Considering that European legislation includes limits for the most toxic aflatoxin B1 alone and the total aflatoxins (sum of aflatoxins B1, B2, G1 and G2) these are of primary focus for any method of analysis. On deciphering the ability of a method to be fit for purpose in a given environment a number of factors need to be considered including: accuracy; limit of detection; application to multiple analytes; versatility; time of analysis; cost; ease of use; low maintenance, repeatability and robustness. Key parameters were considered for both the ToxiMet system and UPLC-MS/MS instrument applied in this study (Table 2). The benefits of the ToxiMet system, compared with UPLC-MS/MS, included its ability to rapidly and simultaneously determine each of the individual aflatoxins, using unskilled personnel working outside of the laboratory environment. Additional benefits were the avoidance of the need for internal and analytical standards and low capital and maintenance costs as compared to the UPLC-MS/MS equipment. The benefit of the UPLC-MS/MS, in addition to being the regulatory method of choice, was the versatility to include other toxins within the analysis of the sample. Nonetheless, the individual determination of aflatoxins B1, B2, G1 and G2 in peanuts, maize, rice and distillers grain samples was shown to be feasible for both methods. The UPLC-MS/MS had the added ability of M1 determination (Supplementary Data). Table 3 summarises the range of the individual toxin concentrations determined by ToxiMet system 
and UPLC-MS/MS analysis for each food and feed commodity. In general the upper limit of the range for the toxin concentration determined by UPLC-MS/MS was higher than for the ToxiMet system. Although the same lot was analysed by both methods these differences in range could be in part due to the variation in sample size from $1 \mathrm{~g}$ to $25 \mathrm{~g}$ taken from the lot as due to the heterogenic nature of mycotoxins this can be critical. Some of these challenges in sampling procedures to detect mycotoxins in agricultural commodities have been well described [31]. On each occasion the ToxiMet system provided an immediate result and did not indicate that the aflatoxin concentration was above an upper limit of detection. However, when the result was beyond the calibration range for UPLC-MS/MS analysis the sample was diluted and re-analysed on the instrument. Recent recommendations provided by the manufacturer since the completion of this study of evaluation of the instrument indicate that a very high levels for a quantitative as opposed to a qualitative result if the sample concentration is greater than $30 \mu \mathrm{g} / \mathrm{kg}$ the sample should be diluted and re-analysed in the same manner as for UPLC-MS/MS. Figure 3 shows the graphical correlation of the results of the Toximet versus UPLC-MS/MS analysis for total aflatoxins (B1, B2, G1, G2) and for B1 determination in rice, maize, peanuts and dried distillers grains. The number and percentage of samples defined to be above the European regulatory limits for each sample type was compared between methods (Table 4).

Rice Samples: For rice included under the EU legislation 165/2010 whereby all cereals and all products derived from cereals, including processed cereal products have the limits of $2.0 \mu \mathrm{g} / \mathrm{kg}$ for aflatoxin B1 and $4.0 \mu \mathrm{g} / \mathrm{kg}$ for total aflatoxins (Sum of B1, B2, G1, G2). However, an exception is for AFB1 in processed cereal-based foods and baby food for infants and young children where the regulated limit is $0.1 \mu \mathrm{g} / \mathrm{kg}$. Therefore, comparing the results from the ToxiMet system and UPLC-MS/MS analysis, 26 out of the 88 samples (29.5\%) analysed by ToxiMet and 21 out of the 88 samples (23.9\%) analysed by UPLC-MS/MS had their levels of aflatoxin B1 higher than the allowed legislation. For B1 analysis the variation arose in 5 samples (7RD2, 1RD3, 3RL3, 2RD4, 4RD4) which displayed results of $2.29,2.48,3.38,2.15$ and $2.24 \mu \mathrm{g} / \mathrm{kg}$ by ToxiMet and $1.11,1.13,1.95,1.16$ and $1.43 \mu \mathrm{g} / \mathrm{kg}$ by UPLC-MS/MS. For total aflatoxins 16 out of the 88 samples (18.2\%) analysed by both ToxiMet system and UPLC-MS/MS were higher than the legislative limit. For total aflatoxins analysis the variation arose in four samples (2RL2, 3RL4, 
9RL1, 1RL4) which displayed results of $2.24,3.55,4.08$ and $5.05 \mu \mathrm{g} / \mathrm{kg}$ by ToxiMet compared to $4.61,4.3,3.21$, and $3.88 \mu \mathrm{g} / \mathrm{kg}$ by UPLC-MS/MS respectively. As observed in Table 3 the range of aflatoxin concentrations and quantification in rice varies slightly between the two methods. The $R^{2}$ correlations of the concentrations determined for $B 1, B 2, G 1, G 2$ and total aflatoxins are $0.90,0.45,0.90,0.54$ and 0.92 (Supplementary data). For B2 and G2 the correlation was poor as the number of positive samples were low and bordering on the limit of quantification for both methods. The concentration range for aflatoxin $M 1$ in the rice samples as determined by UPLC-MS/MS was 0 to $0.82 \mu \mathrm{g} / \mathrm{kg}$ with only 7 samples having measurable levels.

Maize Samples: For maize included under the EU legislation 165/2010 whereby all cereals and all products derived from cereals, including processed cereal products have the limits of $2.0 \mu \mathrm{g} / \mathrm{kg}$ for aflatoxin B1 and $4.0 \mu \mathrm{g} / \mathrm{kg}$ for total aflatoxins (Sum of B1, B2, G1, G2). Again, there is an exception for AFB1 in processed cereal-based foods and baby food for infants and young children where the regulated limit is $0.1 \mu \mathrm{g} / \mathrm{kg}$. Therefore, comparing the results from the ToxiMet system and UPLC-MS/MS analysis, 40 out of the 79 samples (50.6\%) analysed by ToxiMet and 36 out of the 79 samples (45.6\%) analysed by LC-MS/MS had their levels of aflatoxin B1 higher than the allowed legislation. For B1 analysis the variation arose in eight samples (2M1, 3M2, 4M4, 2FP4, 4FP4, 3F4, 2M5, 2F5) which displayed results of 2.23, 0.35, 1.57, 1.53, 0.92, 1.72, 1.87 and $1.25 \mu \mathrm{g} / \mathrm{kg}$ by ToxiMet and 1.67, 4.21, 7.92, 2.02, 2.09, 3.13, 2.36 and $2.23 \mu \mathrm{g} / \mathrm{kg}$ by UPLC-MS/MS. For total aflatoxins 46 out of the 79 (58.2\%) samples analysed by ToxiMet and 40 out of the 79 (50.6\%) samples analysed by LC-MS/MS were higher than the legislative limit. For total aflatoxins analysis the variation arose in six samples (4M2, $3 \mathrm{M} 2,7 \mathrm{M} 3,2 \mathrm{M} 5,7 \mathrm{FP5}, 2 \mathrm{F5})$ which displayed results of 5.59, 1.85, 3.43, 2.42, 2.96 and 3.96 $\mu \mathrm{g} / \mathrm{kg}$ by ToxiMet and 3.11, 11.12, 4.33, 4.04, 5.29 and $7.17 \mu \mathrm{g} / \mathrm{kg}$ by UPLC-MS/MS. Most samples showing variability between the two methods were very close to the action level with the ToxiMet showing marginally lower levels overall compared to the MS method. The main discrepancies were in B1 and G1 values which were higher by UPLC-MS/MS. As observed in Table 3 the range of aflatoxin concentrations and quantification in maize varies at the upper limits of quantification. The $R^{2}$ correlations of the concentrations determined for $B 1, B 2, G 1$, $\mathrm{G} 2$ and total aflatoxins in maize are $0.93,0.51,0.97,0.77$ and 0.94 (Supplementary data). 
Similarly, for B2 and G2 the correlation was poor as the number of positive samples were low and bordering on the limit of quantification for both methods. The concentration range for aflatoxin M1 in the maize samples as determined by UPLC-MS/MS was 0 to $5.33 \mu \mathrm{g} / \mathrm{kg}$ with 29 samples having measurable levels above the $0.05 \mu \mathrm{g} / \mathrm{kg}$ EU level established for M1 in milk (Supplementary data).

Peanut Samples: The EU legislation for groundnuts (peanuts) and processed products thereof intended for direct human consumption or use as an ingredient in foodstuffs is $2 \mu \mathrm{g} / \mathrm{kg}$ for aflatoxin B1 and $4 \mu \mathrm{g} / \mathrm{kg}$ for total aflatoxins. The peanut samples were provided as a homogenate paste which was to be used for direct human consumption. For the analysis the peanut samples were the most difficult to handle. Both the rice and maize samples were a homogenised powder, and as such were easier to aliquot from the sample container. However, the buttery consistency of the peanut samples was troublesome and required more time for the ToxiMet system filtration step. As the extraction solvent was a $60 \%$ methanol solution the aflatoxins would be soluble and pass through the filter but the fats less soluble clogging the filter.

Therefore, comparing the results from the ToxiMet system and UPLC-MS/MS analysis, 70 out of the 71 samples (98.6\%) analysed by both methods had their levels of aflatoxin B1 higher than the allowed legislation and similarly their levels of total aflatoxins higher than the legislative limit. The same single sample was below legislative limits for both methods (1PA4). As observed in Table 3 the range of aflatoxin concentrations and quantification in peanut varies at the upper limits of quantification. The $\mathrm{R}^{2}$ correlations of the concentrations determined for B1, B2, G1, G2 and total aflatoxins in peanuts are $0.22,0.02,0.005,0.14$ and 0.19 (Supplementary data). Although the qualitative comparison for peanuts was excellent relative to the legislative limit the correlation on quantification of the individual toxins was very poor due to samples with extremely high levels of aflatoxin contamination as determined by UPLC-MS/MS. As most samples were heavily contaminated it was impossible to examine the correlation relative to the low regulatory levels. When the quantitative $R^{2}$ correlation was performed for those samples with a total aflatoxins concentration below $250 \mu \mathrm{g} / \mathrm{kg}$ the performance was much improved. The $\mathrm{R}^{2}$ correlations of the concentrations determined for $B 1, B 2, G 1, G 2$ and total aflatoxins in peanuts for these samples was $0.88,0.01,0.90,0.38$ and 0.88. The most interesting point to note was the concentration range for aflatoxin $M 1$ in 
theses peanut samples as determined by UPLC-MS/MS was 0 to $381 \mu \mathrm{g} / \mathrm{kg}$ with only 1 sample with no measurable M1 detected and all others well above the $0.05 \mu \mathrm{g} / \mathrm{kg}$ level established for M1 in milk (Supplementary data).

Dried distillers grains: The EU legislation for dried distillers grains for use as an ingredient in animal feed is $20 \mu \mathrm{g} / \mathrm{kg}$ for aflatoxin B1 and there is currently no regulation for total aflatoxins (Directive 2002/32/EC). Therefore, comparing the results from the ToxiMet system and UPLCMS/MS analysis, none of the 22 samples analysed by ToxiMet or analysed by UPLC-MS/MS had their levels of aflatoxin B1 higher than the recommended EU legislation of $20 \mu \mathrm{g} / \mathrm{kg}$. The $\mathrm{R}^{2}$ correlations of the concentrations determined for $\mathrm{B} 1, \mathrm{B2}, \mathrm{G} 1, \mathrm{G} 2$ and total aflatoxins in these samples was $0.91,0.004,0.47,0.31$ and 0.70 with levels detected by the ToxiMet system generally half of those detected by UPLC-MS/MS. The concentration range for aflatoxin M1 in these samples as determined by UPLC-MS/MS was 0 to $0.78 \mu \mathrm{g} / \mathrm{kg}$ with only 5 samples having no measurable levels. It should be noted that for the dried distillers grains there was no choice for selection of dried distillers grains on the ToxiMet system as a commodity for analysis and as such the proprietary calibrations applied were not specific for this matrix. Therefore, the closest commodity of maize was chosen for the calibration and variations in matrix between maize and dried distillers grains could affect the performance for this commodity. Improved correlations may be obtained if the ToxiMet system is calibrated for this feed material.

The comparison of the testing platforms showed the key attributes, benefits and limitations (Table 2). For the food products collected from the Ivory Coast, the ToxiMet approach displayed a very good correlation with the state of the art confirmatory technique of UPLCMS/MS for the qualitative detection of aflatoxin B1 and total aflatoxins at the European regulatory levels for these sample types. In relation to the quantification of aflatoxin there were significant discrepancies when the toxin levels were high as in the case of the peanut samples and for the B2 and G2 toxins. For the ToxiMet system there appeared to be no upper limit of detection and for all samples a concentration value was provided even if beyond the detection range. The variations in the $B 2$ and $G 2$ toxins may be due to the selectivity of the ToxiSep cartridge especially at high levels of total aflatoxins contamination. Additionally, at higher level of contamination the results might be underestimated as a portion of the aflatoxin target analytes might be lost during sample preparation when the ToxiSep cartridge reaches 
its binding capacity. For the UPLC-MS/MS the use of the calibration curve showed the highly contaminated samples to be off scale and re-dilution was applied where necessary. Other discrepancies in quantification can arise in the homogeneity of the sample mass analysed, the efficiency of the extraction procedures and in the preparation of the analytical standards for the UPLC-MS/MS method. Although the sample was milled and thoroughly mixed the ToxiMet system utilised a more representative $25 \mathrm{~g}$ compared to $1 \mathrm{~g}$ by the UPLC-MS/MS method reducing the potential for toxin hotspots. Generally, the correlation trend of the UPLC-MS/MS method to the ToxiMet system is that the UPLC-MS/MS method detected higher levels of B1 and total aflatoxins. Extraction procedures with multiple steps allow for error and for untrained personal the methods should be as simple as possible. Both methods have solvent based extraction steps with multiple steps for the operator though the ToxiMet system uses only methanol as a solvent and overall is a relatively faster procedure. A major advantage of the ToxiMet system is that analytical standards are not required. For the preparation of calibration standards precision is required for highly sensitive detection methods as even small error margins through solvent evaporation of the stock standard on preparation, storage or pipetting can cause differences in response at the low levels of detection which can amplify to significant differences in the toxin concentration in the sample. The use of internal standards for mass spectrometry procedures would be the preferable option for precision analysis though to date these are only available for certain analytes for mycotoxin analysis and are highly expensive for routine use.

The samples collected in this study from the Ivory Coast were for direct human consumption in the local community. These samples showed high levels of contamination of aflatoxins well above the European regulatory limits in the order of severity of peanuts, maize and rice. To prevent adverse human health effects from high levels of aflatoxin contamination food choices in this region may be an important aspect whereby rice may have less risk for toxic concerns due to the occurrence determined in this study. Innovative cost effective detection can offer a means of prevention of contaminated products entering into the food chain but in regions where food supply is more important than safety from chronic toxin exposure, research and innovation must examine strategic mitigation strategies to ensure sufficient food supply. Limitations of both methods currently lie in their ability to detect AFB1 in processed cerealbased foods and baby food for infants and young children at the regulated limit is $0.1 \mu \mathrm{g} / \mathrm{kg}$ as the 
LODs for B1 using the method are currently $0.5 \mu \mathrm{g} / \mathrm{kg}$ for UPLC-MS/MS and $0.2 \mu \mathrm{g} / \mathrm{kg}$ for ToxiMet. This would potentially pose issues for these commodities unless minor modifications to the sample preparation can be considered for increased sensitivity. Another current limitation of the ToxiMet system is that it currently does not detect aflatoxin M1 or as in comparison to advanced LCMS/MS methods the simultaneous detection of other mycotoxins. The presence of aflatoxin M1 in maize samples highly contaminated with aflatoxin B1 has been reported previously [32]. Similarly Huang and co-workers [33] found aflatoxins $M 1$ and $M 2$ in peanuts with the highest content 64.7 and $3.6 \mu \mathrm{g} / \mathrm{kg}$, respectively. This study highlights in agreement with previous authors that aflatoxin M1 is not only an important contamination concern of milk but that regulation should also be considered for foodstuffs such as peanuts and maize.

\section{Conclusion}

The ToxiMet system provides an alternative significantly lower cost approach compared to mass spectrometry analysis in both instrumentation and maintenance costs and day to day operation of the assay that would be useful for the prevention of highly contaminated foodstuffs with aflatoxins entering the food chain. This type of technology could be suitable for use as a highly accurate food safety monitoring tool in trading, distributing and processing companies in emerging economies where contamination in key staple foods and major export crops can be high as illustrated in this study for maize and peanut samples. Such a system can be useful in laboratories for the determinations and removal of contaminated lots where there are limited resources for highly expensive analytical equipment and trained staff. In agreement with Yao et al 2015 an integrated approach which incorporates rapid sample screening techniques with analytical methods may be most suitable for detecting aflatoxins in consumables. A recommendation for future consideration is for the Toximet technology to undergo a full inter-laboratory trial with the inclusion of certified reference materials against other techniques. Though the inclusion of both methods of analysis in proficiency testing schemes would help determine further the accuracy of each technique especially at key regulatory levels.

\section{Acknowledgements}

This research was funded through the Advanced ASSET project, partly funded through InvestNI and the European Sustainable Programme 2007-2013 under the European Regional 
Development Fund. The authors would like to acknowledge the EuropeAid project 3Clvoire which funded sample collection in the Ivory Coast, preparation of the samples and shipment to Queen's University Belfast for analysis. The authors would like to thank both Laurine Engrand from the Graduate School of Life Sciences of Toulouse ENSAT in France and Elise Lapie from Lasalle Beauvais Polytechnic Institute, France for the contributions to this work during their student placement at the Institute for Global Food Security. 


\section{References}

1. Richard JL (2008) Discovery of aflatoxins and significant historical features. Toxin Reviews, 27 (3-4) 171-201

2. Da Costa CL, Geraldo MRF, Arroteia CC, Kemmelmeier C (2010). In vitro activity of neem oil on Aspergillus flavus growth, sporulation viability of spores, morphology and aflatoxin B1 and B2. Advances in Biosciences and Biotechnology 1: 292-299.

3. Shehu K and Bello MT (2011) Effect of Environmental Factors on the Growth of Aspergillus Species Associated with Stored Millet Grains in Sokoto. Nigerian Journal of Basic and Applied Science, 19(2):218-223

4. Ehrlich KC, Montalbano BG and Cotty PJ (2003) Sequence comparison of afIR from different Aspergillus species provides evidence for variability in regulation of aflatoxin production. Fungal Genetics and Biology 38: 63-74.

5. Medina A, Rodríguez A, Sultan $Y$ and Magan N (2015) Climate change factors and Aspergillus flavus: effects on gene expression, growth and aflatoxin production World Mycotoxin Journal, 8 (2): 171-179

6. Carnaghan RB, Hartley RD, O' Kelly J (1963) Toxicity and fluorescence properties of the aflatoxins. Nature, 200, 1101.

7. Razzaghi-Abyaneh M, Shams-Ghahfarokhi M, Peng-Kuang C (2010) Aflatoxins: Mechanism of inhibition by antagonistic plants and bacteria. (Eds) www.Intechopen.com/books/...586-304.

8. De Longh H, Vles Ro, Van Peltj (1964) Milk of mammals fed an aflatoxin-containing diet. Nature 202, 466

9. Holzapfel CW, Steyn PS, Purchase IF (1966) Isolation and structure of aflatoxins M1 and M2. Tetrahedron Letters 25, 2799

10. Strosnider H, Azziz-Baumgartner E, Banziger M, Bhat RV, Breiman R, Brune MN, DeCock K, Dilley A, Groopman J, Hell K, Henry SH, Jeffers D, Jolly C, Jolly P, Kibata GN, Lewis L, Liu X, Luber G, McCoy L, Mensah P, Miraglia M, Misore A, Njapau H, Ong CN, Onsongo MT, Page SW, Park D, Patel M, Phillips T, Pineiro M, Pronczuk J, Rogers HS, Rubin C, Sabino M, Schaafsma A, Shephard G, Stroka J, Wild C, Williams JT, Wilson D. (2006) Workgroup report: public health strategies for reducing aflatoxin exposure in developing countries. Environmental Health Perspectives; 114(12):1898-1903.

11. Enyiukwu D.N., Awurum A.N., Nwaneri J.A. (2014) Mycotoxins in Stored Agricultural Products: Implications to Food Safety and Health and Prospects of Plant-derived Pesticides as Novel Approach to their Management Greener Journal of Microbiology and Antimicrobials, 2 (3), 32-48 
12. Miller JD (1999). Fungi and mycotoxins in grain: implications for stored products research. Proceedings of the $6^{\text {th }}$ international Working Conference on Stored Product Research. 2, 971-977.

13. Williams JH, Phillips TD, Joll PE, Stiles JK, Jolly CM and Aggarwal D (2004) Human aflatoxicosis in developing countries: a review of toxicology, exposure, potential health consequences and interventions. American Journal of Clinical Nutrition 80 (5), 1106-1122

14. Khlangwiset $P$ and Wu F (2010) Costs and efficacy of public health interventions to reduce aflatoxin-induced human disease. Food Additives and Contaminants Part A Chemical Analysis Control and Exposure Risk Assessment 27 (7) 998-1014.

15. Wild CP, Gong YY (2010) Mycotoxins and human disease: a largely ignored global health issue. Carcinogensis 31 (1) 71-82

16. Reddy KRN, Salleh B, Saad B, Abbas HK, Abel CA, Shier WT (2010) An overview of mycotoxin contamination in foods and its implications for human health. Toxin Reviews 29 (1) 3-26

17. Marin S, Ramos A.J., Cano-Sancho G., Sanchis V (2013) Mycotoxins: Occurrence, toxicology, and exposure assessment Food and Chemical Toxicology 60, 218-237

18. Razzaghi-Abyaneh M, Chang PK, Shams-Ghahfarokhi M and Rai M. (2014) Global health issues of aflatoxins in food and agriculture: challenges and opportunities. Frontiers in Microbiology, 5 (420) 1-3

19. Wu F. (2015) Global impacts of aflatoxin in maize: trade and human health. World Mycotoxin Journal, 8 (2): 137-142

20. International Agency for Research on Cancer (IARC), 1993. IARC Monographs on the Evaluation of Carcinogenic Risks to Humans: Some Naturally Occurring Substances: Food Items and Constituents, Heterocyclic Aromatic Amines and Mycotoxins. IARC Scientific Publications No. 56, IARC, Lyon, France.

21. CAST (2003) Mycotoxins: risks in plant, animal, and human systems. Ames, lowa: Council for Agricultural Science and Technology.

22. Commission Regulation (EC) No 1881/2006 of 19 December 2006 setting maximum levels for certain contaminants in foodstuffs. Official Journal of the European Union L364/5

23. Commission Regulation (EU) No 165/2010 of 26 February 2010 amending Regulation (EC) No 1881/2006 setting maximum levels for certain contaminants in foodstuffs as regards aflatoxins. Official Journal of the European Union L50/8 
24. Commission Regulation (EU) No 1058/2012 of 12 November 2012 amending Regulation (EC) No 1881/2006 as regards maximum levels for aflatoxins in dried figs. Official Journal of the European Union L313/14

25. Yao H, Hruska Z, Diana Di Mavungu, J (2015) Developments in detection and determination of aflatoxins. World Mycotoxin Journal, 8 (2): 181-191

26. Piletska E, Karim K, Coker R, Piletsky S (2010) Development of the custom polymeric materials specific for aflatoxin B1 and ochratoxin A for application with the ToxiQuant T1 sensor tool. Journal of Chromatography A, 1217 (2010) 2543-2547

27. Coker RD, Nagler MJ, Andreou MP (2006) Device for detection and measurement of a target compound such as a food toxin Patent number WO 2006123189 A2

28. Lacina, O., Zachariasova, M., Urbanova, J., Vaclavikova, M., Cajka, T., Hajslova, J. (2012) Critical assessment of extraction methods for the simultaneous determination of pesticide residues and mycotoxins in fruits, cereals, spices and oil seeds employing ultrahigh performance liquid chromatography-tandem mass spectrometry, Journal of Chromatography A, 1262, 8-18.

29. Dzuman Z, Zachariasova M, Lacina O, Veprikova Z, Slavikova P, Hajslova J (2014) A rugged high-throughput analytical approach for the determination and quantification of multiple mycotoxins in complex feed matrices, Talanta, 121, 263-272

30. Oplatowska-Stachowiak M, Haughey SA, Chevallier O, Galvin-King P, Campbell K, Magowan E, Adam G, Berthiller F, Krska R, Elliott CT (2015) The determination of mycotoxin content in dried distillers grain with solubles (DDGS) using a multianalyte UPLC-MS/MS method: Implications for the safe use of this alternative energy source in animal feeds. Journal of Agricultural and food chemistry DOI: 10.1021/acs.jafc.5b03844

31. Whitaker TB, Slate AB, Doko MB, Maestroni BM, Cannavan A. Sampling procedures to detect mycotoxins in agricultural commodities 2011 Springer Netherlands

32. Shotwell OL, Goulden ML, Hesseltine CW (1976) Aflatoxin M1. Occurrence in stored and freshly harvested corn. Journal of Agricultural and Food Chemistry, 24 (3), 683-684

33. Huang B, Han Z, Cai Z, Wu Y, Ren Y (2010) Simultaneous determination of aflatoxins B1, B2, G1, G2, M1 and M2 in peanuts and their derivative products by ultra-highperformance liquid chromatography-tandem mass spectrometry. Analytica Chimica Acta, $662,62-68$ 
Figure 1: Structures of aflatoxin analogues

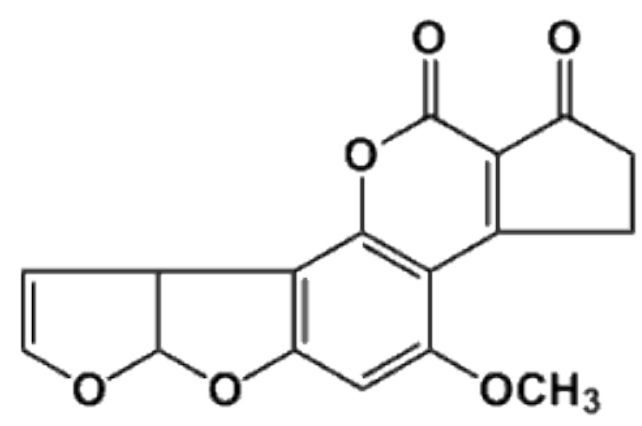

Aflatoxin $B_{1}$

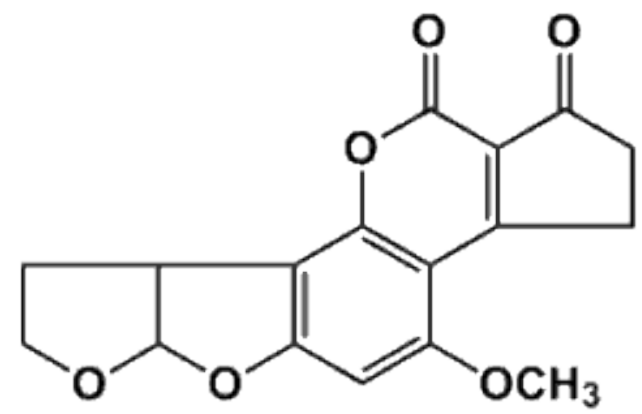

Aflatoxin $\mathrm{B}_{2}$<smiles>COc1cc2c(c3oc(=O)c4c(c13)CCC4=O)C1(O)C=COC1O2</smiles>

Aflatoxin $M_{1}$<smiles>COc1cc2c(c3oc(=O)c4c(c13)CCOC4=O)C1C=COC1O2</smiles>

Aflatoxin $\mathrm{G}_{1}$<smiles>COc1cc2c(c3oc(=O)c4c(c13)CCOC4=O)C1CCOC1O2</smiles>

Aflatoxin $\mathrm{G}_{2}$ 
Figure 2. Retention time separation and multiple reaction monitoring (MRM) transitions of the 5 aflatoxins (B1, B2, G1, G2 and M1) using UPLC-MS/MS.

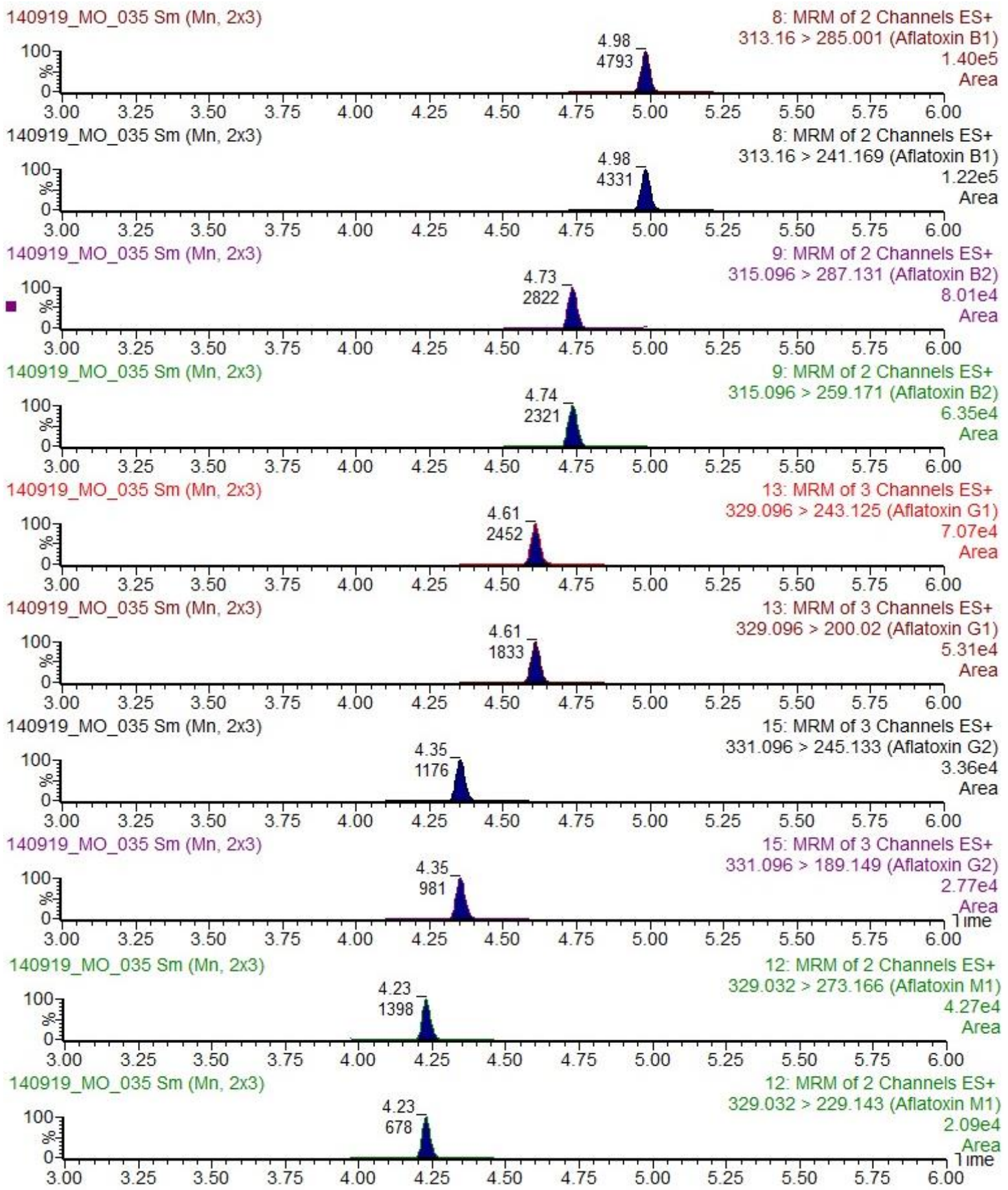


Figure 3: Comparison of UPLC-MS/MS and ToxiMet System Analysis total aflatoxins (B1, B2, $G 1, G 2)$ and $B 1$ determination in rice $(a, b)$, maize $(c, d)$, peanuts $(e, f)$ and dried distillers grain $(g, h)$.
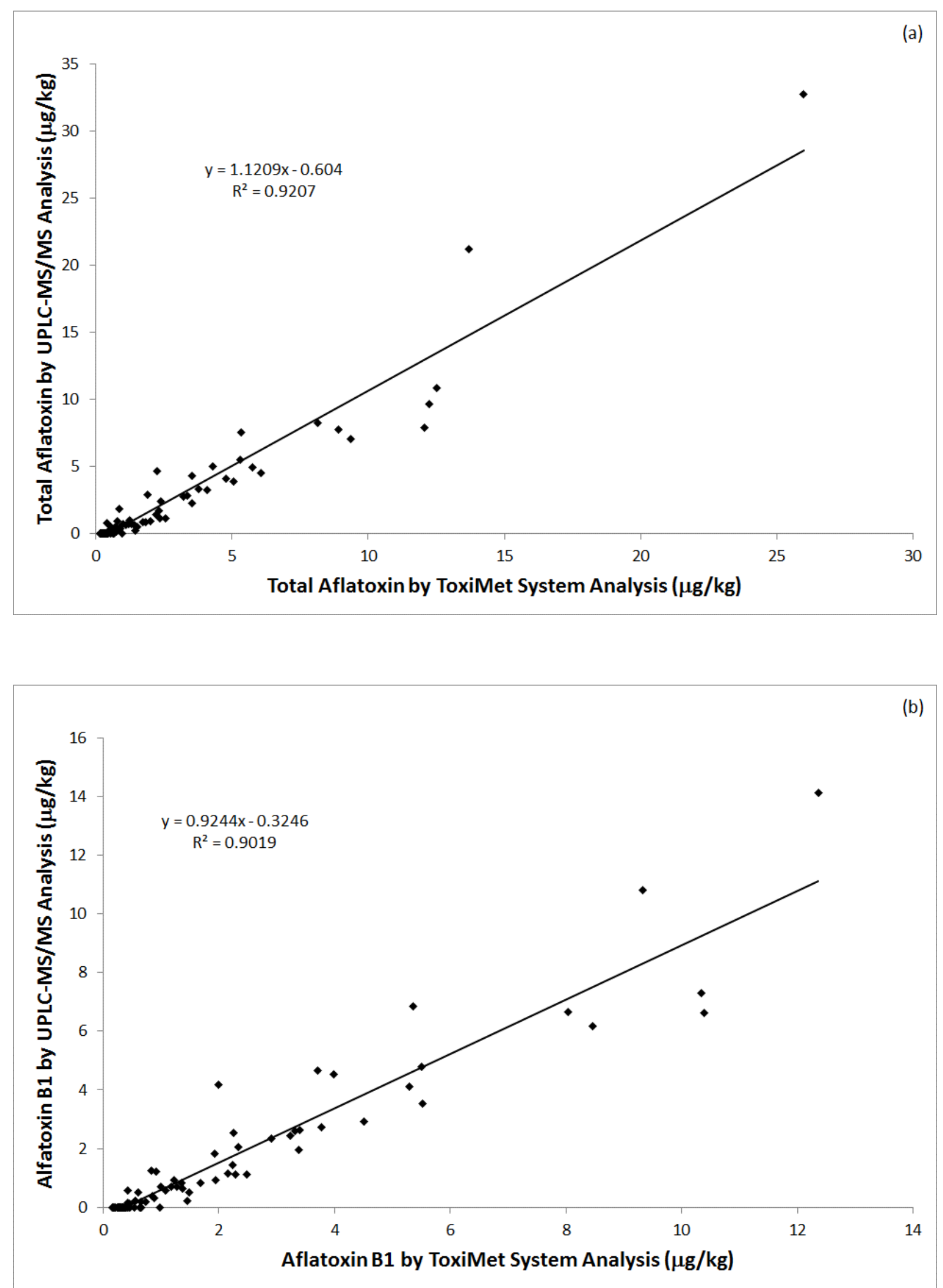

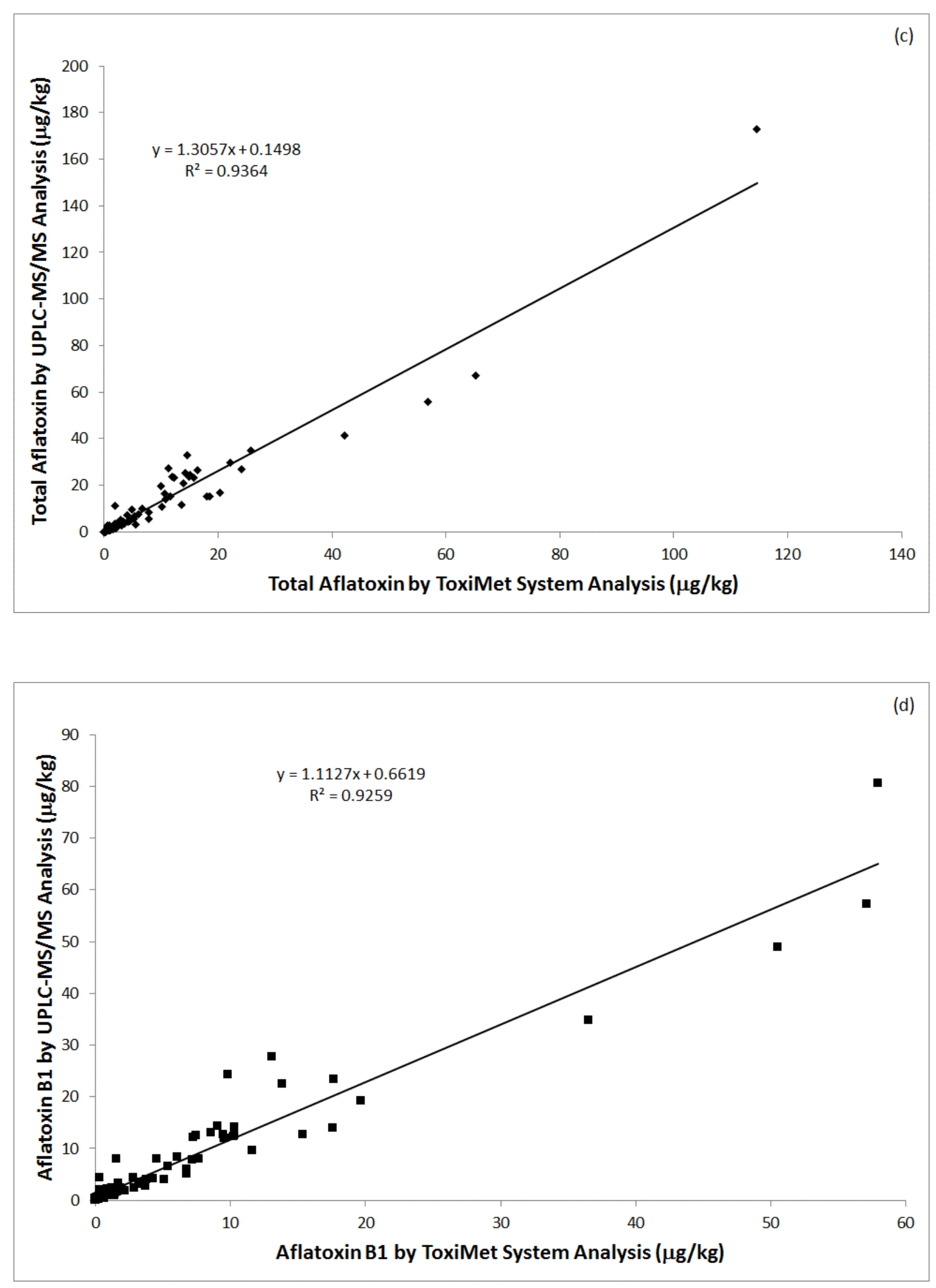

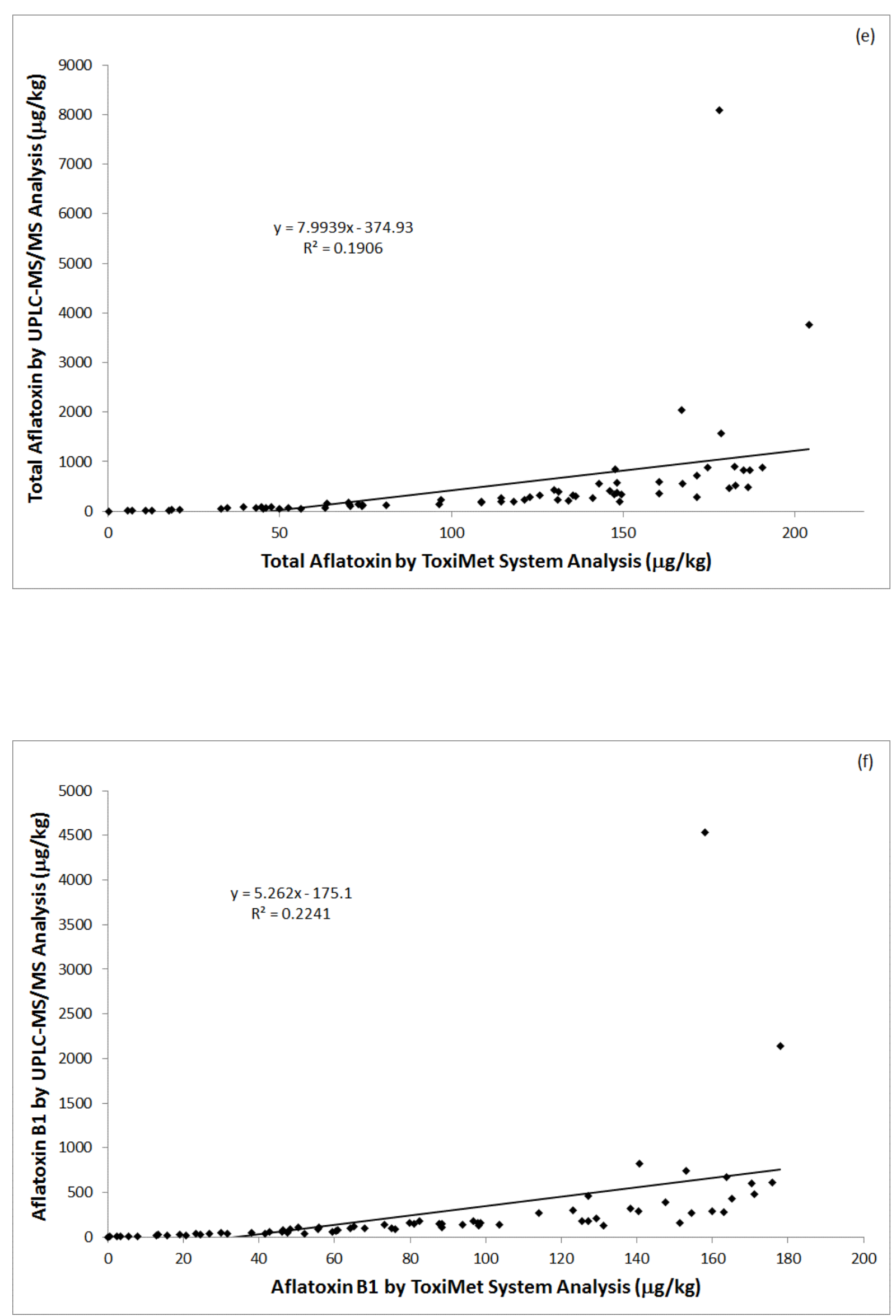

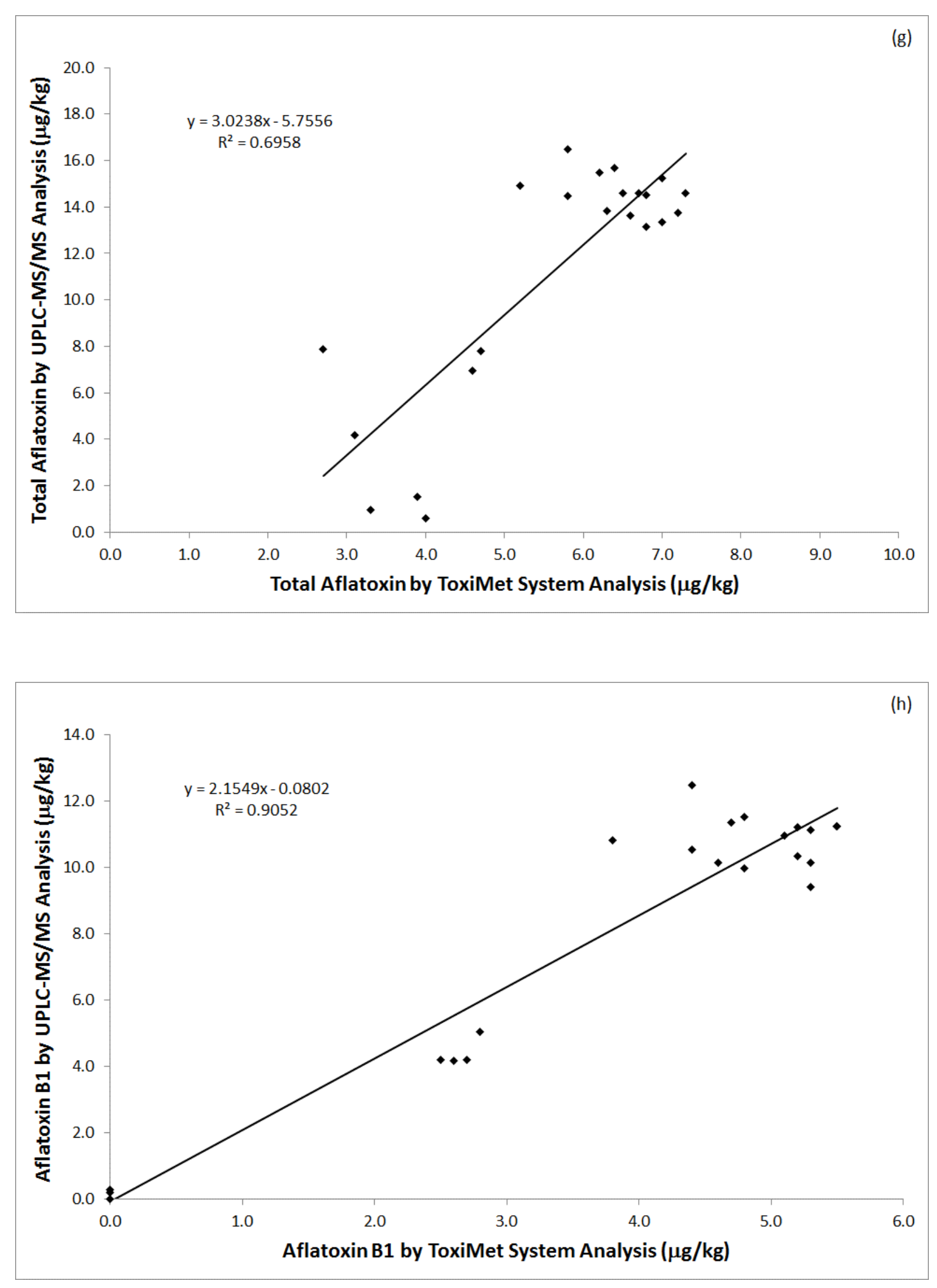
Table 1. The MS/MS conditions for aflatoxins analysis

\begin{tabular}{|c|c|c|c|c|c|c|}
\hline Mycotoxin & $\begin{array}{c}\text { Molecular } \\
\text { weight }\end{array}$ & $\mathrm{RT}$ [min] & $\begin{array}{c}\text { MRM } \\
\text { transitions }\end{array}$ & $\begin{array}{c}\text { Cone } \\
\text { voltage } \\
\text { [V] }\end{array}$ & $\begin{array}{c}\text { Collision } \\
\text { energy } \\
{[\mathrm{eV}]}\end{array}$ & $\begin{array}{c}\text { Dwell } \\
\text { time }[\mathrm{ms}]\end{array}$ \\
\hline \multirow[t]{2}{*}{ Aflatoxin B1 } & \multirow[t]{2}{*}{312.3} & \multirow[t]{2}{*}{5.0} & $313.2>285.0 *$ & 44 & 20 & 4 \\
\hline & & & $313.2>241.2$ & 44 & 36 & 4 \\
\hline \multirow[t]{2}{*}{ Aflatoxin B2 } & \multirow[t]{2}{*}{314.3} & \multirow[t]{2}{*}{4.7} & $315.1>287.1$ & 68 & 24 & 4 \\
\hline & & & $315.1>259.2$ & 68 & 30 & 4 \\
\hline \multirow[t]{2}{*}{ Aflatoxin G1 } & \multirow[t]{2}{*}{328.3} & \multirow[t]{2}{*}{4.6} & $329.1>243.1$ & 14 & 26 & 4 \\
\hline & & & $329.1>200.0$ & 14 & 36 & 4 \\
\hline \multirow[t]{2}{*}{ Aflatoxin G2 } & \multirow[t]{2}{*}{330.3} & \multirow[t]{2}{*}{4.4} & $331.1>245.1$ & 12 & 28 & 5 \\
\hline & & & $331.1>189.1$ & 12 & 36 & 5 \\
\hline \multirow[t]{2}{*}{ Aflatoxin M1 } & \multirow[t]{2}{*}{328.3} & \multirow[t]{2}{*}{4.2} & $329.0>273.2$ & 2 & 42 & 5 \\
\hline & & & $329.0>229.1$ & 2 & 22 & 5 \\
\hline
\end{tabular}

* Transition in bold was used for quantification. 
Table 2: Comparison of testing platforms showing the key attributes, benefits and limitations

\begin{tabular}{|c|c|c|}
\hline Attribute & ToxiMet System & UPLC-MS/MS \\
\hline Analysis & Aflatoxins B1, B2, G1 and G2 & $\begin{array}{c}\text { Aflatoxins B1, B2, G1, G2, M1 } \\
\text { The current UPLC-MS/MS method operating in both } \\
\text { positive and negative mode and requiring sample } \\
\text { injection in two different mobile phases can detect a } \\
\text { total of } 79 \text { mycotoxins }\end{array}$ \\
\hline $\begin{array}{c}\text { Sensitivity } \\
\text { (ppb) }\end{array}$ & $\begin{array}{l}\text { B1: LOD: } 0.20 \text { LOQ: } 0.67 \\
\text { B2: LOD: } 0.12 \text { LOQ: } 0.40 \\
\text { G1: LOD: } 0.21 \text { LOQ: } 0.72 \\
\text { G2: LOD: } 0.04 \text { LOQ: } 0.14\end{array}$ & $\begin{array}{l}\text { B1 LOD: } 0.05 \text {, LOQ: } 0.25 \\
\text { B2 LOD: } 0.125 \text {, LOQ: } 0.25 \\
\text { G1 LOD: } 0.125 \text {, LOQ: } 0.25 \\
\text { G2 LOD: } 0.125 \text {, LOQ: } 0.25 \\
\text { M1 LOD: } 0.05 \text {, LOQ: } 0.25\end{array}$ \\
\hline Specificity & Specific for Aflatoxins B1, B2, G1, G2, & $\begin{array}{l}\text { Very specific for Aflatoxins B1, B2, G1, G2, M1 but } \\
\text { method can be expanded to include a high number of } \\
\text { mycotoxins for which standards were available }\end{array}$ \\
\hline Ease of use & $\begin{array}{l}\text { Method is relatively easy to use but } \\
\text { requires initial training. }\end{array}$ & $\begin{array}{l}\text { Skilled personnel with previous experience in LC-MS/MS } \\
\text { methods and associated software for operation and } \\
\text { interpretation of toxin profiles is required. }\end{array}$ \\
\hline $\begin{array}{l}\text { Amount of sample } \\
\text { (g) }\end{array}$ & 25 & 1 \\
\hline Sample Preparation & $\begin{array}{l}\text { Sample Extraction with filter clean up } \\
\text { ToxiSep Clean Up with filter clean up } \\
\text { ToxiTrace Immobilisation }\end{array}$ & $\begin{array}{l}\text { Sample Extraction using QuEChERS } \\
\text { Centrifugation } \\
\text { C18 Silica sorbent clean up } \\
\text { Centrifugation } \\
\text { Nitrogen Evaporation } \\
\text { Filtering }\end{array}$ \\
\hline $\begin{array}{l}\text { Number of samples } \\
\text { analysed in one } \\
\text { round of } \\
\text { preparation }\end{array}$ & 20 & 30 \\
\hline $\begin{array}{l}\text { Speed of analysis } \\
\text { per sample }\end{array}$ & $<1$ hour & 5 hours \\
\hline $\begin{array}{l}\text { Speed of analysis } \\
\text { for one round of } \\
\text { samples }\end{array}$ & $\begin{array}{l}\text { Toxin Extraction: } 2.5 \mathrm{hr} \\
\text { ToxiQuant Instrument Analysis: } \\
\qquad 0.45 \mathrm{hr} \\
\text { Result Determination for } 4 \text { toxins: } \\
\text { Immediate }\end{array}$ & $\begin{array}{c}\text { Toxin Extraction: } 4 \mathrm{hr} \\
\text { Instrument Analysis: } 19 \mathrm{hr} \text { aflatoxins only } \\
38 \mathrm{hr} \text { all mycotoxins } \\
\text { Result Determination: } 2 \mathrm{hr} \text { aflatoxins } \\
\text { (including interpretation to the calibration curve) }\end{array}$ \\
\hline Portability & $\begin{array}{l}\text { May be applied outside the } \\
\text { laboratory setting at different testing } \\
\text { points along the food chain with } \\
\text { basic facilities to allow for sample } \\
\text { preparation }\end{array}$ & Not possible \\
\hline Benefits & $\begin{array}{l}\text { Relatively fast real time result, highly } \\
\text { sensitive, highly specific multiplex } \\
\text { analysis of four aflatoxins. There is no } \\
\text { requirement for the purchase or } \\
\text { preparation of analytical standards. }\end{array}$ & $\begin{array}{l}\text { Accurate identification and quantification for compounds } \\
\text { with available standards. Analytical standards grade or } \\
\text { internal standards for aflatoxins are available but due to } \\
\text { expense are not routinely used in analysis but are used } \\
\text { for instrument calibration. }\end{array}$ \\
\hline Limitations & $\begin{array}{l}\text { Biosensor is relatively inexpensive } \\
\text { requiring little maintenance and very } \\
\text { limited training in use. }\end{array}$ & $\begin{array}{l}\text { Equipment is highly expensive and requires substantial } \\
\text { maintenance, requiring fully trained personnel for } \\
\text { operation }\end{array}$ \\
\hline
\end{tabular}


Table 3: Range of aflatoxin concentrations determined by each method for each sample type

\begin{tabular}{|c|c|c|c|c|c|c|c|}
\hline Sample Type & $\begin{array}{c}\text { Method of } \\
\text { Analysis }\end{array}$ & $\begin{array}{c}\text { B1 } \\
(\mu \mathrm{g} / \mathrm{kg})\end{array}$ & $\begin{array}{c}\text { B2 } \\
(\mu \mathrm{g} / \mathrm{kg})\end{array}$ & $\begin{array}{c}\text { G1 } \\
(\mu \mathrm{g} / \mathrm{kg})\end{array}$ & $\begin{array}{c}\text { G2 } \\
(\mu \mathrm{g} / \mathrm{kg})\end{array}$ & $\begin{array}{c}\text { Total } \\
(\mu \mathrm{g} / \mathrm{kg})\end{array}$ & $\begin{array}{c}\text { M1 } \\
(\mu \mathrm{g} / \mathrm{kg})\end{array}$ \\
\hline \multirow{2}{*}{$\begin{array}{l}\text { Peanuts } \\
(n=71)\end{array}$} & ToxiMet & $0-178$ & $0-10.6$ & $0-47.9$ & $0.12-11.1$ & $0.23-204.0$ & N/A \\
\hline & $\begin{array}{c}\text { UPLC- } \\
\text { MS/MS }\end{array}$ & $0.63-4535$ & $1.05-1098$ & $0.72-2193$ & $0.71-267.4$ & $1.4-8094$ & $0-381.1$ \\
\hline \multirow{2}{*}{$\begin{array}{l}\text { Maize } \\
(n=79)\end{array}$} & ToxiMet & $0-57.9$ & $0-8.5$ & $0-39.3$ & $0-8.9$ & $0.01-114.6$ & N/A \\
\hline & $\begin{array}{c}\text { UPLC- } \\
\text { MS/MS }\end{array}$ & $0-80.5$ & $0-7.0$ & $0-83.6$ & $0-3.8$ & $0-172.7$ & $0-5.3$ \\
\hline \multirow{2}{*}{$\begin{array}{c}\text { Rice } \\
(n=88)\end{array}$} & ToxiMet & $0.16-12.4$ & $0-2.9$ & $0-8.8$ & $0-1.9$ & $0.15-26.0$ & N/A \\
\hline & $\begin{array}{l}\text { UPLC- } \\
\text { MS/MS }\end{array}$ & $0-14.1$ & $0-1.1$ & $0-16.6$ & $0-0.9$ & $0-32.7$ & $0-0.8$ \\
\hline \multirow{2}{*}{$\begin{array}{l}\text { Dried distillers } \\
\text { grains } \\
\qquad(n=22)\end{array}$} & ToxiMet & $0-5.5$ & $0-2.8$ & $0-1.2$ & $0.1-0.4$ & $2.7-7.3$ & N/A \\
\hline & $\begin{array}{c}\text { UPLC- } \\
\text { MS/MS }\end{array}$ & $0-12.5$ & $0-3.7$ & $0-2.9$ & $0-0.5$ & $0.6-16.5$ & $0-0.8$ \\
\hline
\end{tabular}


Table 4: Number of samples above the regulatory level by each method

\begin{tabular}{|c|c|c|c|}
\hline Sample Type & Regulatory level & $\begin{array}{l}\text { Number of samples } \\
\text { above the regulatory } \\
\text { levels by ToxiMet }\end{array}$ & $\begin{array}{c}\text { Number of samples above } \\
\text { the regulatory levels by } \\
\text { UPLC-MS/MS }\end{array}$ \\
\hline \multirow{2}{*}{$\begin{array}{c}\text { Rice } \\
(n=88)\end{array}$} & $\begin{array}{c}\text { B1 } \\
(>2 \mu \mathrm{g} / \mathrm{kg})\end{array}$ & $26(29.5 \%)$ & $21(23.9 \%)$ \\
\hline & $\begin{array}{c}\text { Total } \\
(>4 \mu \mathrm{g} / \mathrm{kg})\end{array}$ & $16(18.2 \%)$ & $16(18.2 \%)$ \\
\hline \multirow{2}{*}{$\begin{array}{l}\text { Maize } \\
(n=79)\end{array}$} & $\begin{array}{c}\text { B1 } \\
(>2 \mu \mathrm{g} / \mathrm{kg})\end{array}$ & 40 (50.6\%) & $36(45.6 \%)$ \\
\hline & $\begin{array}{c}\text { Total } \\
(>4 \mu \mathrm{g} / \mathrm{kg})\end{array}$ & $46(58.2 \%)$ & $40(50.6 \%)$ \\
\hline \multirow{2}{*}{$\begin{array}{l}\text { Peanuts } \\
(n=71)\end{array}$} & $\begin{array}{c}\text { B1 } \\
(>2 \mu \mathrm{g} / \mathrm{kg})\end{array}$ & 70 (98.6\%) & 70 (98.6\%) \\
\hline & $\begin{array}{c}\text { Total } \\
(>4 \mu \mathrm{g} / \mathrm{kg})\end{array}$ & 70 (98.6\%) & 70 (98.6\%) \\
\hline $\begin{array}{l}\text { Dried distillers } \\
\text { grains }(n=22)\end{array}$ & $\begin{array}{c}\text { B1 } \\
(>20 \mu \mathrm{g} / \mathrm{kg})\end{array}$ & 0 & 0 \\
\hline
\end{tabular}

